\title{
New Evidence for an Active Role of Aluminum in Alzheimer's Disease
}

\author{
D.R. Crapper McLachlan, W.J. Lukiw and T.P.A. Kruck
}

\begin{abstract}
Application of molecular biological techniques and sensitive elemental analysis have produced new evidence implicating aluminum as an important factor in down regulation of neuronal protein metabolism. Aluminum in Alzheimer's disease may act by electrostatically crosslinking proteins, particularly the methionine containing histone $\mathrm{H} 1^{\circ}$, and DNA. The consequence of such crosslinking is reduced transcription of at least one neuron specific gene, the low molecular weight component of neurofilaments. In the superior temporal gyrus in Alzheimer's disease, down regulation of this gene occurs in approximately $86 \%$ of surviving neurons and, therefore, aluminum must be considered as having an active role in the pathogenesis. Epidemiological studies are reviewed that independently support the hypothesis that environmental aluminum is a significant risk factor. Preliminary evidence also suggests that a disorder in phosphorylation may be an important initiating factor.
\end{abstract}

RÉSUMÉ: Nouvelles observations en faveur d'un rôle actif de l'aluminium dans la maladie d'Alzheimer L'application de techniques de biologie moléculaire et de méthodes sensibles d'analyse élémentaire nous ont permis de mettre en évidence de nouveaux indices impliquant l'aluminium comme facteur important dans la régulation à la baisse du métabolisme des protéines neuronales. L'aluminium pourrait agir dans la maladie d'Alzheimer (MA) par la formation de ponts électrostatiques entre les protéines, particulièrement l'histone $\mathrm{H} 1^{\circ}$ contenant de la méthionine, et l'ADN. La conséquence de l'établissement de ces ponts est de réduire la transcription d'au moins une gène spécifique au neurone, celui de la composante de poids moléculaire bas des neurofilaments. Dans le gyrus temporal supérieur des patients atteints de $\mathrm{MA}$, la régulation à la baisse de ce gène survient dans à peu près $86 \%$ des neurones restants. On doit donc considérer que l'aluminium joue un rôle actif dans la pathogénèse de la maladie. Nous revoyons les études épidémiologiques qui supportent de façon indépendante l'hypothèse que l'aluminium environnemental est un facteur de risque significatif. Des données préliminaires suggèrent également qu'une anomalie de la phosphorylation peut être un facteur important amorçant le processus.

Can. J. Neurol. Sci. 1989; 16: $490-497$

Despite intensive investigation world-wide, the etiology of senile and presenile dementia of the Alzheimer type remains unknown. The etiology is most probably multifactorial and dependent upon genetic and environmental determinants. Applications of molecular biological techniques together with neurochemistry are beginning to provide a more precise understanding of the molecular events underlying this baffling neurodegenerative disorder.

Among the environmental factors implicated in Alzheimer's disease $(A D)$, aluminum has often been suggested but analytical difficulties and the limitations of instrumental detection continue to contribute to a controversy regarding its role in $\mathrm{AD}$. The new evidence presented here for a role of aluminum has resulted from an examination of nuclear mechanisms involved in the regulation of gene expression.

Historically, aluminum was reported to be a selective neurotoxin in 18971 and was shortly thereafter recognized as a human poison which caused loss of memory, jerking movements and impaired coordination. ${ }^{2}$ Intensive modern investigations into aluminum toxicity were initiated by the work of Klatzo et $\mathrm{al}^{3}$ and Terry and Pena ${ }^{4}$ who reported that intracranial injection of small doses of soluble aluminum salts in rabbit induced an encephalopathy associated with the intraneuronal accumulation of dense bundles of $10 \mathrm{~nm}$ filaments. Sections examined with a Norelco Electron Probe Analyser detected a trace of aluminum in the affected areas in rabbit brain, but similar scans of autopsied human neurofibrillary tangles from AD patients did not reveal even traces of aluminum. ${ }^{4}$ The apparent absence of increased amounts of the element and the morphological differences between the paired helical filaments of AD brain ${ }^{5}$ and the $10 \mathrm{~nm}$ straight filaments of aluminum induced neurofibrillary degeneration made aluminum an unlikely factor in the disease.

The development of the very sensitive and reproducible technique of flame atomic absorption spectrophotometry in the

From the Department of Physiology, University of Toronto, Toronto

Reprint requests to: D.R. Crapper McLachlan, Department of Physiology, Room 3318, Medical Sciences Building, University of Toronto, Toronto, Ontario, Canada M5S IA8 
1960's, followed shortly by the development of electrothermal carbon furnace technology, permitted, for the first time, the accurate and reliable measurement of aluminum in human tissue samples as small as 10 to $20 \mathrm{mg}$ dry weight. Current atomic absorption spectrophotometry (AAS) is capable of reliable measurement of as little as 30 to $100 \mathrm{pg}$ of aluminum in a biological matrix. Some workers, using AAS and the modern, sensitive, trace element imaging techniques ${ }^{6}$ coupled with neurochemical subcellular fractionation, have found elevated amounts of aluminum in AD tissues and argued that aluminum may be an important pathogenic factor.

\section{Aluminum in Alzheimer's Disease}

\section{A) Bulk Tissue Content}

Application of AAS to bulk tissue samples from regions of $\mathrm{AD}$ affected neocortex, revealed a wide range of aluminum concentrations: approximately thirty per cent of samples contained aluminum concentrations more than three standard deviations above the mean found in samples from frontal, temporal and parietal gray matter of age-matched controls (control mean $=1.8$ $\pm 0.8 \mu \mathrm{g} / \mathrm{g}$ dry SD; $\mathrm{n}=208$ ). 7,8 While the mean neocortical tissue concentration of aluminum in $\mathrm{AD}$ neocortex was only elevated to about twice that found in control tissue $(3.6 \pm 2.9 \mu \mathrm{g} / \mathrm{g}$ $S D ; n=377$ from 14 brains; $p<.0002$ ), aluminum induced a lethal encephalopathy in cats and rabbits at average brain aluminum concentrations as low as $5.6 \pm 1.2 \mu \mathrm{g} / \mathrm{g}$ dry. ${ }^{9}$ Furthermore, the experimental encephalopathy was associated with a delay in onset of a progressive learning-memory deficit, $10-14$ which appeared before other neurological signs. The observation that about $20 \%$ or more of $\mathrm{AD}$ neocortical regions exhibited aluminum concentrations in the toxic range for certain laboratory animals, justified further testing of the hypothesis that aluminum was important in the disease.

Although Trapp et al ${ }^{15}$ also reported a small but statistically significant elevation in bulk tissue aluminum content in AD tissues, McDermott et all6 reported an increase in aluminum with age but no specific increase in AD. A subsequent interlaboratory investigation revealed that the probable explanation for the failure of the McDermott et al studies to detect aluminum in Alzheimer's disease involved differences in sample size and case selection. ${ }^{17}$ Employing the analytical technique of neutron activation, Markesbery et al 18,19 also found no difference in bulk brain levels for aluminum between control and AD patients. Instrumental neutron activation is based on the thermal neutron reaction ${ }^{27} \mathrm{Al}(\mathrm{n} \gamma)^{28} \mathrm{Al}$. Without pre-irradiation separation, aluminum assay in tissue is difficult and often inaccurate because of the interfering ${ }^{31} \mathrm{P}(\mathrm{n}, \alpha)^{25} \mathrm{Al}$ reaction from fast neutrons in the conventional nuclear reactors usually used for this analysis. The errors introduced by neutron activation methods performed in the presence of fast neutrons upon small tissue samples at low aluminum concentrations ( 1 and $8 \mu \mathrm{g} / \mathrm{g}$ ) are unacceptable for investigating aluminum in $\mathrm{AD} .{ }^{20}$

Importantly, Traub et al ${ }^{21}$ demonstrated that brain destruction alone, specifically Creutzfeldt-Jakob disease, did not elevate brain aluminum as measured by atomic absorption spectroscopy. Each of the analytical studies involving bulk tissue reported only small increases, much smaller than that associated with dialysis encephalopathy where the association between alu- minum and the neurological dysfunction is more clearly evident. ${ }^{22}$ The studies of Hershey et al ${ }^{23}$ and Shore and Wyat ${ }^{24}$ failed to produce evidence for a general body overload of aluminum in $\mathrm{AD}$ and concluded that any cellular $\mathrm{Al}$ accumulation may be a secondary effect of neurons that are degenerating. Overall, measures of bulk tissue content in themselves failed to produce sufficient evidence to support an important role for aluminum in $A D$.

\section{B) Intracellular Localization}

Aluminum accumulates on at least five intracellular sites in $A D$ : intranuclear, on neurofibrillary tangles, amyloid cores of senile plaques, in ferritin and in lysosomes.

Perl and Brody25,26 and Perl and Pendlebury27 developed techniques for determining elemental content in individual neurons employing scanning electron microscopy in conjunction with energy-dispersive $\mathrm{x}$-ray analysis and more recently elemental analysis with the laser microprobe mass analyser. ${ }^{6}$ Using 20 $\mu \mathrm{m}$ thick formalin fixed sections, Perl and co-workers reported elevated aluminum in the nuclear region and in neurofibrillary tangles from $\mathrm{AD}$ tissue. When applied to tissues from patients with the Parkinsonism dementia and amyotrophic lateral sclerosis syndromes of Guam, Perl, et al ${ }^{28}$ and Garruto et al ${ }^{29}$ reported very high aluminum signals from neurons with neurofibrillary tangles. Kobayashi et al ${ }^{30}$ reported a case of AD with Balint's syndrome who worked as an aluminum refiner and whose neurons with neurofibrillary tangles exhibited high aluminum signals using wavelength-dispersive $\mathrm{X}$-ray microanalysis. Tangle bearing neurons from a sporadic AD case and a case of subacute sclerosing panencephalitis, both of whom had no unusual exposure to aluminum, did not exhibit a detectable aluminum signal. Kobayashi et al concluded that aluminum deposition does not necessarily contribute to the formation of tangles but is due to environmental exposure. While the North American cases of $\mathrm{AD}$ reported by Perl and co-workers had no known industrial exposure to aluminum, this element does appear to be more bioavailable in the environment of Guam than two control islands, Palau and Jamaica. ${ }^{31}$ Whether instrumental sensitivity accounts for the differences in Perl's and Kobayashi's observations on aluminum content in neurons with neurofibrillary degeneration in sporadic disease remains to be resolved. What role, if any, aluminum might have in the formation of $A D$ neurofibrillary degeneration is unknown. Immunological evidence indicates that the paired helical filaments of $A D$ tangles are composed of a family of phosphorylated microtubule associated proteins, Tau, ${ }^{32}$ neurofilament- $\mathrm{M}$ and $-\mathrm{H}^{33}$ and ubiquitin, ${ }^{34}$ whereas the aluminum-induced tangle is immunologically quite different and composed of phosphorylated neurofilaments. 35 Since phosphate groups are high affinity intracellular ligands for aluminum, passive accumulation upon AD neurofibrillary tangles cannot be excluded. The imaging techniques have not revealed metals with high phosphate affinity other than aluminum. Hence, if passive accumulation of aluminum is the correct explanation, the degenerating neuron must be selectively permeable to this element. Also unknown is whether aluminum bound to phosporylated peptides would change the activity of degradative enzymes and permit the accumulation of incompletely degraded proteinaceous material which might contribute to the AD tangle. There is, however, no direct evidence that aluminum is causal in the formation of $\mathrm{AD}$ neurofibrillary tangles. 
Senile plaque cores have also been reported to exhibit increased aluminum content. Duckett and Galle, ${ }^{36}$ using the microprobe de Castaing which employs wavelength X-ray spectrometry for elemental detection, reported finding aluminum and silicon in the senile plaque. Recently Candy and colleagues ${ }^{37}$ also reported accumulation of aluminum and silicon in plaque cores. They isolated senile plaques from homogenized tissue which was treated with pronase, sodium dodecyl sulfate, hydroxylamine and differential centrifugation. Solid state nuclear magnetic resonance studies indicated alumino-silicate compounds in which aluminum is in a tetrahedral configuration, as it is in the catalytic crackers of carbon-carbon bonds used in the petroleum industry. Critical evaluation of procedural contamination is required to evaluate the biological significance of these observations. As in the case of neurofibrillary degeneration, there is no direct evidence that aluminum contributes to the formation of senile plaques.

Ferritin is an ubiquitous iron storage protein composed of two types of subunit: heavy $\mathrm{Mr}: 21,000$ and light $\mathrm{Mr}: 19,000$. The molecule is multifunctional and detoxifies, stores and transports iron. Ferritin also functions as a zinc and beryllium detoxicant and, in the presence of a reductant, it releases $\mathrm{Fe}^{++}$which can facilitate the generation of free radicals. Fleming and Joshi ${ }^{38}$ reported that rats on $100 \mu \mathrm{m}$ aluminum chloride in drinking water for one year had $274 \%$ more aluminum per mol of brain ferritin than control but the aluminum content in liver ferritin was not significantly different from control. Furthermore, the amount of ferritin extracted from 2 AD brains was 5.6-fold higher than that found in 2 control brains $(p<0.01)$. Fleming and Joshi ${ }^{38}$ speculated that the increase in aluminum bound to ferritin in AD may be a result of a general increase in the availability of aluminum to brains of AD patients. Why the aluminum treated rat livers did not exhibit elevated aluminum in ferritin is unclear, but there appear to be differences in the proportion of heavy and light chain components in liver and brain ferritin. Whether there is a microheterogeneity in ferritin in human brain which is correlated with $\mathrm{AD}$ requires further investigation, particularly in Down's syndrome and familial AD.

While aluminum accumulation upon each of the above compartments could theoretically contribute to neuronal dysfunction in $\mathrm{AD}$, there is no convincing experimental evidence, at present, that aluminum does indeed exert an important role through any of these mechanisms.

\section{Aluminum AND Gene EXPRESSION}

Of the several analytical methods available for measuring trace amounts of aluminum, only the application of techniques employing atomic absorption spectrophotometry have consistently revealed the presence of aluminum in the normal human brain.7,8,12,15,21 Atomic absorption methods applied to sub-cellular fractionation have revealed that $95 \%$ of aluminum measured in bulk cerebral grey matter is found within the nuclear compartment. ${ }^{39}$ Within the nucleus, $81 \%$ of the bulk tissue aluminum content of control neocortex is associated with the highly condensed, transcriptionally inert, heterochromatin. This fraction accounts, in human cerebral cortex, for only $25 \%$ of the total DNA.40 In contrast, the euchromatin fraction, a portion of which contains transcriptionally active DNA and which accounts for $75 \%$ of total DNA in human cerebral cortex, con- tains only $14 \%$ of total tissue aluminum. A selective increase in aluminum concentration in this vital compartment would have a relatively small influence on bulk tissue aluminum concentrations but a powerful influence upon gene transcription and DNA repair. Recent experimental measurements in our laboratory indicate that a 9-fold increase in aluminum content does, indeed, occur within a small sub-compartment of transcriptionally active chromatin in AD.

\section{Chromatin Structure and Gene Expression in Alzheimer's Disease}

Several different methods have indicated that chromatin structure in cerebral cortex is affected by AD and is shifted toward a more condensed form than what is found in age matched controls. ${ }^{40,41}$ Furthermore, among the adult dementias, the change appears to be specific to AD. 42 While the precise biochemical changes responsible for DNA compaction in $A D$ remains unknown, the DNA involved in the compaction process includes neuron-specific functionally important genes. The most extensively studied gene at this time is the low molecular weight moiety of neuronal neurofilaments (NF-L) and the 5' flanking region for this gene. Employing the low molecular weight (17kD) enzyme, micrococcal nuclease, which selectively digests the linker regions between nucleosomes, we found that, in comparison with controls, AD neocortical gray matter nuclei are more slowly digested, and the ratio of dinucleosomes to mononucleosomes is increased. 41 More recent examination of the nucleosome fractions has revealed that $\mathrm{AD}$ mononucleosomes contain only $14 \%$ as much of the 5 ' flanking region of NF-L as do those from controls. This 5' flanking region contains the RNA polymerase promoter, such as the TATAA motif, and transcription modulatory elements. In contrast, AD dinucleosome fractions contain $143 \%$ more of the 5' flanking region than do control dinucleosomes. This implies that the 5' regulator region of the gene for the low molecular weight moiety of neurofilaments is less accessible to the attack of enzymes, including RNA polymerase, in AD than in controls. Thus, AD is associated with an inhibition of the initiation of transcription and this change probably accounts for the reduced messenger RNA reported for the low molecular weight moiety of neurofilaments 43,44 Previous work has demonstrated that the dinucleosome fraction released from $A D$ neocortex contains an increased proportion of the methionine containing linker histone $\mathrm{H} 1^{\circ}$ but not other $\mathrm{H} 1$ proteins.

The dinucleosome fraction released by light micrococcal nuclease digestion of neocortical nuclei was examined for trace metal content. Twenty-three metals were examined by inductively coupled plasma emission spectroscopy and atomic absorption spectroscopy. Only aluminum was found to be elevated. In 16 brains prepared from individuals with no history of dementia and no AD histopathology, the average aluminum content in the dinucleosome fraction from randomly selected neocortical areas from all four lobes was found to be $545 \pm 245$ SD $\mu \mathrm{g} \mathrm{Al} / \mathrm{g}$ DNA. Furthermore, in 7 brains of patients with a dementia process other than that found in $A D$ and without $A D$ histopathology, an average aluminum content of $838 \pm 436 \mathrm{SD}$ $\mu \mathrm{g} / \mathrm{g}$ of DNA was encountered. This non-AD demented control group included 2 brains from patients with dialysis encephalopathy in which the bulk neocortical grey matter alu- 
minum content ranged between $20-40 \mu \mathrm{g} / \mathrm{g}$ dry weight. These brains did not demonstrate elevated intranuclear aluminum. In contrast, the neocortex sampled randomly from cortical regions from 18 brains with a history of dementia and the typical AD histopathological changes had an average aluminum content of $2,515 \pm 978 \mathrm{SD} \mu \mathrm{g} / \mathrm{g}$ of DNA. Importantly, in the age range $76-$ 89 , dinucleosomes prepared only from the superior temporal gyrus contained $337 \pm 103 \mu \mathrm{g} / \mathrm{g}$ in controls and $3,170 \pm 1086 \mathrm{SD}$ $\mu \mathrm{g} \mathrm{Al} / \mathrm{g} \mathrm{DNA}$ in the $\mathrm{AD}$ group. These findings indicate that aluminum does not accumulate with chronological aging in the healthy brain; the nuclear accumulation is associated specifically with AD pathology. These data also indicate that the fraction associated with increased $\mathrm{H} 1^{\circ}$, reduced digestibility and an increased proportion of DNA associated with the 5' flanking region of at least one neuron-specific gene is associated with an increase in aluminum content. The central question is whether the accumulation is merely a secondary consequence of the degenerative process, or whether the accumulation has pathophysiological importance.

\section{Linker Histone Affinity for DNA in the Presence of AlUMINUM}

The binding of proteins to DNA is dependent upon electrostatic interactions between the positively charged side groups of the lysine rich linker histones and the polyanionic phosphorous backbone of DNA and/or metal ion bridges between acidic amino acid terminals and the oxygens of the DNA polyphosphate backbone. From the above measures of aluminum content in dinucleosomes and measures of the linker histone content of dinucleosomes extracted from control and AD-affected neocortex, it is possible to estimate how many aluminum atoms, on average, accumulate on this fraction in AD. In control neocortical dinucleosomes, isolated exclusively from Brodmann A22, there are 5 aluminum atoms and 1.43 linker histones per 400 base pairs (bp). Assuming random distribution, 3-4 aluminum atoms are associated with each histone of the $\mathrm{H} I$ family. In AD, on the average, there are 23 aluminum atoms and $2.26 \mathrm{HI}$ molecules per $400 \mathrm{bp}$, or 10 aluminum atoms per $\mathrm{Hl}$ molecule. In $\mathrm{AD}$, however, the non-methionine containing $\mathrm{H} 1$ histones are not increased but the $\mathrm{H}^{\circ}$ and $\mathrm{HI}^{\circ}$ proteins are increased. ${ }^{42}$ Indeed, there is a statistically significant correlation between the amount of $\mathrm{Hl}^{\circ}$ measured in an AD dinucleosome fraction and the abundance of aluminum associated with that fraction of chromatin ( $n=9, r=0.777, p=0.0137$ ). Therefore, assuming that the increase in histone $\mathrm{HI}^{\circ}$ and $\mathrm{HI}^{\circ 0}$ is associated with the increase in aluminum, there would be, on average, 22 aluminum atoms associated with each of the $\mathrm{H}^{\circ} \mathrm{H}^{\circ}$ molecules in the dinucleosome fraction in AD. These mean estimates do not indicate whether the aluminum atoms found in $A D$ are associated with DNA phosphate, protein-DNA interactions, or the protein itself. The numbers, however, are useful in estimating the plausibility of results obtained from in vitro studies of aluminumDNA interactions.

Lukiw et al 45 employed sodium ions to displace chromosomal proteins electrostatically from DNA in order to investigate further the chromatin changes associated with AD. By increasing the ambient sodium ion concentration, a characteristic dissociation curve for chromatin proteins was generated and quantitatively analyzed on polyacrylamide gels. The results indicated that the linker histone $\mathrm{HI}$ and $\mathrm{HI}^{\circ}$ in nuclei prepared from $\mathrm{AD}$ neocortex have a greater affinity for DNA than do those in nuclei extracted from controls matched for age and postmortem delay. Aluminum salts added in vitro to control human nuclei in concentrations approaching those found in AD (30 aluminum atoms per $200 \mathrm{bp}$ ) changed the salt elution profile to one closely resembling that found in $\mathrm{AD}$ (see Figure 2 in Lukiw et $\mathrm{a}^{45}$ ). One interpretation is that aluminum increases the stability of the histone-DNA complex. Since dinucleosomes extracted from randomly selected $A D$ neocortex contain 5 to 9 -fold more aluminum than do controls, aluminum could stabilize the binding of linker histones to DNA and therefore inhibit the initiation of transcription. Such an action of aluminum would be of pathological significance.

It is noteworthy that aluminum results in a delayed reduction in NF-L mRNA in the experimentally-induced progressive encephalopathy of rabbits. 46.47

Further, unpublished observations from this laboratory have recently shown that employing mobility shift assays to monitor specific linker histone-DNA complexation and $\mathrm{NaCl}$-induced dissociation to measure the stability of these complexes, $\mathrm{HI}^{\circ}$ linker histone-DNA complexes formed in the presence of aluminum lactate are more refractory to salt induced dissociation than those formed in the presence of sodium lactate.

\section{SUMmary: Evidence for AN ACTIVE ROLE FOR Aluminum in Alzheimer's Disease}

The experimental evidence indicates that one important neurotoxic action of aluminum in $\mathrm{AD}$ affected neocortex may be to increase the binding of histones, particularly $\mathrm{HI}^{\circ}$, to DNA which results in increased compaction of chromatin and reduced transcription. The supporting evidence includes:

1) A statistically reliable correlation between the aluminum to DNA ratio on intermediate euchromatin and the amount of highly condensed transcriptionally inactive heterochromatin found in any given preparation from AD affected neocortex. ${ }^{39}$

2) A nine-fold increase in aluminum content in $A D$ in the diand tri- nucleosome fraction released by light micrococcal nuclease digestion of nuclei from superior temporal gyrus grey matter as compared to age matched controls. Compared to age matched control dinucleosomes, the $A D$ dinucleosomes also contain an increased abundance of the linker histone $\mathrm{HI}^{\circ}$ and an increased proportion of DNA containing the promoter region of the gene coding for NF-L.

3. In vitro evidence that $\mathrm{AD}$ linker histones bind more tightly to DNA than do control and that aluminum, added in vitro at concentrations found in AD chromatin to nuclei extracted from normal control brain, enhances DNA-protein binding of $\mathrm{HI}$ and $\mathrm{H}^{\circ} .45$

4) Results of a mobility shift assay which indicate that aluminum, in vitro, selectively binds human $\mathrm{Hl}^{\circ}$ to a $300 \mathrm{bp}$ human DNA fragment in a crude extract of $5 \%$ perchloric acid soluble nuclear proteins.

5) The statistically significant relation between the amount of $\mathrm{H} 1^{\circ}$ and the amount of aluminum in dinucleosome preparations prepared from AD neocortex.

6) The marked and cell specific reduction in NF-L mRNA in anterior horn cells when aluminum is experimentally applied to rabbit CNS. 46 
The amount of aluminum found in $\mathrm{AD}$ dinucleosomes plausibly accounts for the increased binding of linker histones to DNA, which results in a shift in the promotor region of at least one neuron specific gene, NF-L, to a transcriptionally inactive dinucleosome fraction. These observations plausibly explain the non-random reduction in abundance of certain RNAs, particularly that for NF-L.43.44 Independent support for the hypothesis that aluminum is an important pathogenic factor in $\mathrm{AD}$ comes from epidemiological studies.

\section{Epidemiology: Aluminum and Alzheimer's Disease}

Five epidemiological studies have reported that increased aluminum concentrations in drinking water, superimposed upon an already high daily dietary aluminum intake (about $10 \mathrm{mg} / 24$ hours), increases the incidence of AD. $48-52$

An important epidemiological study by Martyn et al ${ }^{52}$ has recently been reported. These workers examined the incidence of presenile $A D$ in 88 county districts in England by examining the records of computerized tomographic scanning units that served the districts. Two control groups were collected: a group with dementia and multiple infarcts visible in the CT scans $(n=519)$ and a group with late onset epilepsy without clinical dementia $(n=2,920)$. The experimental group was composed of presenile (65 years of age or younger) patients with probable $A D(n=445)$ and possible $A D(n=221)$. The presenile group was chosen because younger AD patients were considered to be more likely to undergo intensive investigation and therefore to be more accurately reported. The incidence of each of these diseases in the catchment areas was correlated with aluminum content in the drinking water. No statistically significant relative risk between aluminum in the drinking water and multi-infarct dementia or adult onset epilepsy was found. However, compared to regions in which the aluminum in drinking water was less than $10 \mu \mathrm{g} / \mathrm{l}$, the prevalence of $\mathrm{AD}$ increased progressively to reach a relative risk of 1.7 in regions containing aluminum at $111 \mu \mathrm{g} / \mathrm{l}$ or more (confidence interval 1.1-2.7).

Two epidemiological studies have been conducted in Norway. Vogt ${ }^{49}$ tested the hypothesis that a relation (co-variance) exists between the concentration of aluminum in the drinking water and the frequency of $\mathrm{AD}$. This study reported a statistically significant increased mortality rate from this disease with increased aluminum concentration. Mortality rates from presenile and senile dementia during the period 1969-1983 were evaluated for a standard population of $3,250,000$ people. The data were divided into two groups: a) The record on death certificates of presenile or senile dementia as the primary cause of death; this accounted for 1,504 cases. b) Presenile or senile dementia mentioned as one of four associated conditions at death; this occurred in 16,560 certificates. AD is the most common cause of senile dementia ( $50-75 \%$ of cases), but the second most common cause (10\% to $20 \%$ ) is multi-infarct dementia which is secondary to vascular disease of the brain. Therefore, the death certificates were examined for evidence of disease of the circulatory system including ischemic heart disease, cerebral vascular disease, hypertensive disease, and diabetes mellitus. Death associated with paralysis agitans was also recorded. Vogt divided the population of Norway into five zones. The zones were based on increasing concentrations of aluminum in lakes which corresponds well with the aluminum found in drinking water. Zone 1 contained the lowest amount of aluminum (20 $\mu \mathrm{g} / \mathrm{l})$ and Zone 5 , in the southeastern most region of Norway, the highest $(200 \mu \mathrm{g} / \mathrm{l})$. Zones 4 and 5 received the largest amounts of acid rain and therefore had the highest concentration of bioavailable aluminum. Zone 5 had significantly higher mortality from senile and presenile dementia, and the risk of dying of dementia was approximately 1.48 times higher than in Zone 1. The age distributions and numbers of individuals at risk for AD were approximately the same in each of the zones. Furthermore, there was no difference between the risk factors for cerebral vascular disease and multi-infarct dementia between the zones. The risk of dying of parkinsonism was also not related to bioavailable aluminum. Flaten 50 correlated the incidence of dementia with aluminum in the drinking water and obtained a similar, highly significant result. These data further support the growing body of evidence implicating aluminum in $\mathrm{AD}$.

Still and Kelley ${ }^{48}$ examined first admission cases to the State Mental Health Hospitals between 1971 and 1979 in three counties of South Carolina: Anderson, Horry, and York. These cases were age $\mathbf{5 5}$ years or older and were classified as having primary degenerative dementia, vascular dementia, and alcoholic/other dementia. The three counties were selected because Horry County has $4.18 \mathrm{mg}$ of fluoride per liter of drinking water, whereas Anderson and York Counties have .49 and $0.61 \mathrm{mg} / \mathrm{l}$ respectively. Aluminum and fluoride are mutually antagonistic in competing for absorption in the gut. The more fluoride in the diet the less aluminum is absorbed. In the classification of the authors, primary degenerative dementia was taken to be predominantly AD. Employing a $2 \times 2$ Chi-square distributions test there were significant differences between Horry-Anderson and Horry-York Counties in the number of cases of primary degenerative disease cases, whereas no significant differences in the number of cases occurred between York and Anderson Counties. There were no significant differences between the counties in the number of first admissions with a diagnosis of vascular dementia or alcoholic/other dementia. Per 100,000 population, the high fluoride area had approximately $19 \%$ as many cases of putative $A D$ as did the low fluoride counties.

None of the epidemiological studies are without criticism and they must be considered as preliminary. No study employed autopsy confirmation or attempted to estimate the probable diagnostic accuracy of death certificates or of admission diagnoses. No assessment of how closely the samples reflected the true prevalence of the disease was carried out. The British study conducted by Martyn et al ${ }^{52}$ has the highest probability of accurate diagnosis. Notwithstanding the shortcomings of the currently available epidemiological reports, however, the studies reach the same conclusion: that aluminum in drinking water, in addition to a large daily intake of aluminum through the respiratory and alimentary systems, increases the risk of AD. The importance of this conclusion demands that further studies be rigorously pursued. A more realistic assessment of the aluminum risk requires comparison of populations with a lifetime history of low total body exposure to aluminum compared to populations exposed to high concentrations, a condition difficult to achieve for such an ubiquitous element.

\section{Mechanisms of Aluminum Uptake in Alzheimer's Disease}

There appear to be three routes by which aluminum may gain access to the nuclear compartment in AD. 


\section{Uptake Hypothesis I, Defective Exclusion Barriers}

$A D$ is associated with a defect in the blood-brain barrier for, or the intracellular compartmentalization of, this highly neurotoxic element. In renal patients undergoing dialysis blood aluminum concentrations rise ten to fifty fold above those found in the presence of normal renal function. After prolonged dialysis, bulk grey matter aluminum concentrations may rise many fold higher than those reported for AD. Only in the range of bulk grey matter concentrations of 20 to $40 \mu \mathrm{g} / \mathrm{g}$ dry weight are neurological signs encountered 22 and the ensuing encephalopathy is unassociated with AD histopathology. Galle (personal communication) and $\mathrm{Perl}^{6}$ have found that high concentrations of aluminum are detectable in lysosomes of astrocytes. Aluminum injected intracerebrally in rabbits induces an increase in the number of lysosomes, 53 and lysosomes localize aluminum. ${ }^{54}$ Unpublished work from this laboratory, employing the morin stain for the detection of aluminum in dialysis encephalopathy brains, also localized aluminum in the cytoplasm of astrocytes and did not reveal elevated amounts of aluminum in the nucleus. Importantly, increased amounts of aluminum were not detected in nuclear preparations from cerebral grey matter of patients with dialysis encephalopathy ${ }^{39}$ or in dinucleosomes released by mild micrococcal nuclease digestion as measured with atomic absorption spectroscopy. (Lukiw and McLachlan, unpublished observations). In the presence of renal failure and markedly elevated serum aluminum concentrations, the healthy brain appears to sequester aluminum into non-toxic cytoplasmic compartments, thereby tolerating a high tissue burden without evidence of cytoplasmic or nuclear toxicity. The dialysis encephalopathic syndrome apparently occurs at high tissue concentrations of aluminum when the capacity for detoxification is exceeded.

In $A D$, relatively small amounts of aluminum accumulate on both neurofibrillary tangles and potentially toxic nuclear structures. Changes in brain lysosomal activity have been reported by Bowen and Davidson. ${ }^{55}$ Hypothesis I argues that the primary etiological event which causes $\mathrm{AD}$ reduces the capacity of the blood-brain barrier and lysosomal systems to sequester aluminum. The increase in aluminum in brain ferritin ${ }^{38}$ may also reflect increased availability of aluminum in AD affected brain cells. This hypothesis does not exclude other cellular consequences of the primary etiological event. Further investigation of the blood-brain barrier and lysosomal system is required to test this hypothesis adequately.

\section{Uptake Hypothesis II, Ligand Enhanced Uptake}

The healthy human blood-brain barrier is extremely effective in preventing aluminum from gaining access to brain tissue. However, brain uptake is also influenced by the ligand to which aluminum is bound, both in the gastrointestinal tract and in plasma. Recent experiments by Kruck et al 56,57 indicate that, for rabbits administered the equivalent of the adult human $(70 \mathrm{~kg})$ standard oral antacid dose of aluminum as the hydroxide, citrate or maltolate, the maltolate resulted in higher serum levels, urinary excretion and neurotoxicity within 15 days. Plasma aluminum levels were raised 3.2 and 2.7 -fold by the hydroxide and citrate, respectively, and 52-fold by the maltolate. Urinary aluminum output was increased 5 -fold by the hydroxide and citrate and 90 -fold by the maltolate. Whether these marked differences are related to the higher lipid solubility as measured by the octanol/water ratio for aluminum maltolate, 58 or to a membrane transport system recognizing maltol, is uncertain. However, since maltol is a common food substance and readily forms aluminum maltolate, an unusually high exposure to aluminum bound to ligands which are readily taken up by the brain and capable of bypassing the blood-brain barrier is a route by which abnormally high concentrations of aluminum could accumulate. Ligand-enhanced brain uptake of aluminum could explain how aluminum in drinking water might become a risk factor.

\section{Uptake Hypothesis III, Marker for Altered Phosphorylation}

An intranuclear accumulation of aluminum has been demonstrated by DeBoni et al ${ }^{59}$ and Wen and Wisniewski ${ }^{60}$ employing the histochemical stain morin, as well as by direct analytical methods including atomic absorption spectroscopy ${ }^{39}$ and $x$-ray image analysis. ${ }^{25}$ Considering the $6.8 \times 10^{9}$ bp (about $1.4 \times 10^{10}$ phosphates) typical of diploid human DNA, additional nascent and processed ribonucleic acids and free nucleotide pools contained within a typical nuclear volume of about $300 \mu \mathrm{m},{ }^{3}$ the nucleus contains the highest phosphate density, and hence potential aluminum binding capacity, of any cellular organelle (Lukiw et al). ${ }^{63}$ Concentrations of phosphate are $2 \mathrm{mmol} / \mathrm{l}$ in plasma, $10 \mathrm{mmol} / \mathrm{l}$ in the cytosol and at least $50 \mathrm{mmol} / \mathrm{l}$ within the nucleus. The high phosphate density within the nucleus provides a high affinity, high capacity repository which traps aluminum in the nucleus. But why is there an increase of aluminum on the repressed gene fraction enriched in dinucleosomes in $\mathrm{AD}$ ?

One possibility is that the primary etiological event results in overphosphorylation of nuclear protein, particularly the linker histones. Considerable evidence indicates that several of the constituents of AD neurofibrillary tangles are hyperphosphorylated; they include Tau, ${ }^{32}$ MAP-2,61 neurofilament NF-H and -M. ${ }^{35}$ Whether the disorder in phosphorylation involves hyperphosphorylation or a failure to dephosphorylate certain intraneuronal proteins, the hyperphosphorylated sites may act as sinks, or ligands of high stability, for aluminum. Following aluminum binding, changes in conformation, as is known for aluminum binding to calmodulin, 62 may result in impaired degradation of the hyperphosphorylated peptide. In any event, aluminum would serve as a very stable electrostatic crossbridge and could exert an active role in the pathogenesis of the disease by reducing the probability of repair and impairing the normal mechanisms controlling homeostasis.

Chronic, low dose oral aluminum administration in rats also increases phosphorylation of MAP-2 proteins by about $150 \%$ and of NF-H by about $150 \%$ to $200 \%$. Aluminum also increases cyclic AMP and cyclic GMP in rat 65 and Johnson and Jope speculate that aluminum may exert a toxic role in $A D$ through effects upon phosphorylation. The molecular biology of the phosphorylation mechanisms in $A D$ requires further investigation to resolve these unanswered questions.

\section{Conclusion}

Recent rapid progress in the molecular biology of AD more strongly implicates aluminum in the pathogenesis than previously suspected. One role of aluminum appears to involve the nonrandom down regulation of the transcription of neuron specific genes through increased electrostatic binding of proteins, particularly $\mathrm{H} 1^{\circ}$, to DNA. The mechanisms that determine the non- 
random alteration in transcription have not yet been identified, nor have the population of genes affected in AD been fully characterized. Nevertheless, the neurochemical and epidemiological evidence together are sufficiently strong to warrant that serious consideration be given to restricting bioavailable aluminum in populations at risk for $\mathrm{AD}$ until the many unanswered questions are more fully addressed.

\section{ACKNOWLEDGEMENTS}

Supported by the Medical Research Council of Canada, Ontario Mental Health Foundation, Natural Sciences and Engineering Research Council, and Scottish Rite Charitable Foundation.

\section{REFERENCES}

1. Döllken P. Üeber die Wirkung des Aluminum mit besonderer Berücksichtigung der durch das aluminum verursachten Lasionen im Zentralnervensystem. Naunyn-Schmiedebergs Arch exper Path Pharmakol 1897; 40: 58-120.

2. Spofforth J. Case of aluminum poisoning. Lancet 1921; 1: 1301

3. Klatzo I, Wisniewski $\mathrm{H}$, Streicher E. Experimental production of neurofibrillary degeneration 1: Light microscopic observations. J Neuropathol Exp Neurol 1965; 24: 187-199.

4. Terry RD, Pena C. Experimental production of neurofibrillary degeneration 2: Electromicroscopy, microscopy, phosphatase, histochemistry and electron probe analysis. J Neuropathol Exp Neurol 1965; 24: 200-210.

5. Kidd M. Alzheimer's disease: An electron microscopical study. Brain 1964; 87: 307.

6. Perl DP. Aluminum: Methodologic approaches. In: Sigel H, Sigel A, eds. Metal Ions in Biological Systems, Vol. 24, Aluminum and its Role in Biology. New York: Marcel Dekker, 1988: 259. 283.

7. Crapper DR, Krishnan SS, Dalton AJ. Brain aluminum distribution in Alzheimer's disease and experimental neurofibrillary degeneration. Science 1973; 180: 511-513.

8. Crapper DR, Krishnan SS, Quittkat S. Aluminum, neurofibrillary degeneration and Alzheimer disease. Brain 1976; 99: 67-79.

9. De Boni U, Otvos A, Scott JW, et al. Neurofibrillary degeneration induced by systemic aluminum. Acta Neuropathol (Berl) 1976; 35: 285-294.

10. Crapper DR, Dalton AJ. Alterations in short term retention, conditioned avoidance response acquisition and motivation following aluminum induced neurofibrillary degeneration. Physiol Behav 1973; 10: 925-933.

11. Crapper DR, Dalton AJ. Aluminum induced neurofibrillary degeneration, brain electrical activity and alterations in acquisition and retention. Physiol Behav 1973; 10: 935-945.

12. Petit TL, Biederman GB, McMullen PA. Neurofibrillary degeneration, dendritic dying back, and learning-memory deficits after aluminum administration: implications for brain aging. Exp Neurol 1980; 67: 152-162.

13. Rabe A, Lee $M H$, Shek $J$, et al. Learning deficit in immature rabbits with aluminum-induced neurofibrillary changes. Exp Neurol 1982; 76: 441-446.

14. Yokel RA. Repeated systemic aluminum exposure effects on classical conditioning of the rabbit. Neurobehav Toxicol Teratol 1983; 5: $41-46$.

15. Trapp GA, Miner GD, Zimmerman RL, et al. Aluminum levels in brain in Alzheimer's disease. Biol Psychiatry 1978; 13: 709-718.

16. McDermott JR, Smith AI, Iqbal K, et al. Brain aluminum in aging and Alzheimer disease. Neurology 1979; 29: 809-814.

17. Crapper McLachlan DR, Krishnan SS, Quittkat S, et al. Brain aluminum in Alzheimer's disease: Influence of sample size and case selection. Neurotoxicology 1980; 1: 25-32.

18. Markesbery WR, Ehmann WD, Hussain TIM, et al. Instrumental neutron activation analysis of brain aluminum in Alzheimer disease and aging. Ann Neurol 1981; 10: 511-516.

19. Markesbery WR, Ehmann WD, Alauddin M. Bulk brain concentrations in Alzheimer's disease. In: Wills MR, Savoy J, eds.
Aluminum Analysis in Biological Materials. Charlottesville: University of Virginia Press, 1983: 103-110.

20. Krishnan SS, Harrison JE, McLachlan DRC. Origin and resolution of the aluminum controversy concerning Alzheimer neurofibrillary degeneration. Biological Trace Element Research 1987; 13 : 35-42.

21. Traub RD, Rains TC, Garruto RM, et al. Brain destruction alone does not elevate brain aluminum. Neurology 1981; 31: 986-90.

22. Alfrey AC, LeGendre GR, Kaehny WD. The dialysis encephalopathy syndrome. Possible aluminum intoxication. $\mathrm{N}$ Engl J Med 1976; $294:$ 184-188.

23. Hershey CO, Hershey LA, Varnes A, et al. Cerebrospinal fluid trace element content in dementia: Clinical, radiological and pathologic correlations. Neurology 1983; 33: 1350-1353.

24. Shore D, Wyatt RJ. Aluminum and Alzheimer's disease. J Nerv Ment Dis 1983; 171: 553-558.

25. Perl DP, Brody AR. Alzheimer's disease: X-ray spectrometric evidence of aluminum accumulation in neurofibrillary tangle-bearing neurons. Science 1980; 208: 297-299.

26. Perl DP, Brody AR. Detection of aluminum by SEM-x-ray spectrometry within neurofibrillary tangle bearing neurons of Alzheimer's disease. Neurotoxicology 1980; 1: 133-137.

27. Perl DP, Pendlebury WW. Aluminum accumulation in neurofibrillary tangle-bearing neurons of senile dementia, Alzheimer's type: Detection by intraneuronal X-ray spectrometry studies of unstained tissue sections. J Neuropathol Exp Neurol 1984; 43: 349.

28. Perl DP, Gajdusek DC, Garruto RM, et al. Intraneuronal aluminum accumulation in amyotrophic lateral sclerosis and parkinsonism dementia of Guam. Science 1982; 217: 1053-1054.

29. Garruto RM, Fukaton, R, Yanigahara R, et al. Imaging of aluminum and calcium in neurofibrillary tangle-bearing neurons in Parkinsonism dementia of Guam. Proc Natl Acad Sci USA 1948; 81: 1875-1879.

30. Kobayashi S, Hirota N, Saito K, et al. Aluminum accumulation in tangle-bearing neurons of Alzheimer's disease with Balint's syndrome in a long-term aluminum refiner. Acta Neuropathol (Berl) 1987; 74: 47-52.

31. McLachlan Crapper DR, McLachlan CD, Krishnan B, et al. Aluminum and calcium in Guam, Palau and Jamaica: Implications for amyotrophic lateral sclerosis and Parkinsonismdementia syndromes of Guam. Environmental Geochemistry and Health (in press).

32. Grundke-Iqbal I, Iqbal K, Quinlan M., et al. Microtubule-associated protein Tau: A component of Alzheimer paired helical filaments. J Biol Chem 1986; 261: 6084-6089.

33. Selkoe DJ. Altered structural proteins in plaques and tangles: What do they tell us about the biology of Alzheimer's disease? Neurobiol Aging 1986; 7: 425-432.

34. Mori H, Kondo J, Ihara Y. Ubiquitin is a component of paired helical filaments in Alzheimer's disease. Science 1987; 235: 1641. 1644.

35. Sternberger NH, Stemberger LA, Ulrich J. Aberrant neurofilament phosphorylation in Alzheimer's disease. Proc Natl Acad Sci USA $1985 ; 82: 4274-4276$.

36. Duckett S, Galle P. Mise en évidence de l'aluminum dans les plaques de la maladie d'Alzheimer; etudie a la microsonde de Castaing. C R Seances Acad Sci [D] 1976; 282: 393-395.

37. Candy JM, Klinowski RH, Perry EK, et al. Aluminosilicates and senile plaque formation in Alzheimer's disease. Lancet 1986; 1 : 354-357.

38. Fleming J, Joshi JG. Ferritin: Isolation of aluminum-ferritin complex from brain. Proc Natl Acad Sci USA 1987; 84: 7866-7870.

39. Crapper DR, Quittkat $S$, Krishnan SS, et al. Intranuclear aluminum content in Alzheimer's disease, dialysis encephalopathy. Acta Neuropathol (Berl) 1980; 50: 19-24.

40. Crapper DR, Quittkat S, De Boni U. Altered chromatin conformation in Alzheimer's disease. Brain 1979; 102: 483-495.

41. Lewis PN, Lukiw WJ, De Boni U, et al. Changes in chromatin structure associated with Alzheimer's disease. J Neurochem 1981; 37: 1193-1202.

42. McLachlan Crapper DR, Lewis PN, Lukiw WJ, et al. Chromatin structure in dementia. Ann Neurol 1984; 15:329-334 
43. McLachlan Crapper DR, Lukiw WJ, Wong AL, et al. Selective messenger RNA reduction in Alzheimer's disease. Mol Brain Res 1988; 3: 255-262.

44. Krekoski CA, Clark AW, Parhad IM, et al. Altered expression of neurofilament and other neuronal mRNAs in Alzheimer (AD) cortex. Satellite Meeting of the International Society for Molecular Biology: Molecular and Cellular Biology of Intermediate Filaments, Montreal, 1988; Abstract \#46.

45. Lukiw WJ, Kruck TPA, McLachlan Crapper DR. Alteration in human linker histone-DNA binding in the presence of aluminum salts in vitro and in Alzheimer's disease. Neurotoxicology 1987; 8: 291-302.

46. Muma NA, Troncoso JC, Hoffman P, et al. Aluminum neurotoxicity - altered expression of cytoskeletal genes. Mol Brain Res 1988; 3: 115-122.

47. Parhad IM, Krekoski CA, Mathew A, et al. Neurofilament gene expression in aluminum myelopathy. Symposium on Molecular and Cellular Biology of Intermediate Filaments, Montreal, 1988; Abstract.

48. Still CN, Kelley P. On the incidence of primary degenerative dementia vs. water fluoride content in South Carolina. Neurotoxicology 1980; 4: 125-131.

49. Vogt T. Water quality and health - study of a possible relationship between aluminum in drinking water and dementia (Sosiale og okonomiske studier 61, English abstract), Oslo: Central Bureau of Statistics of Norway. 1986.

50. Flaten TP. Geographical associations between aluminum in drinking water and registered death rates with dementia (including Alzheimer's disease) in Norway. Proceedings from the Second International Symposium on Geochemistry and Health, London (in press).

51. Leventhal GH. Alzheimer's disease and environmental aluminum in Maryville and Morristown, Tennessee, Ph.D. Thesis, University of Tennessee, 1986.

52. Martyn CN, Osmond C, Edwardson JA, et al. Geographical relation between Alzheimer's disease and aluminum in drinking water. Lancet 1989; 1: 59-62.

53. Gruca S, Wisniewski HM. Cytochemical study on the effect of aluminum on neuronal golgi apparatus and lysosomes. Acta Neuropathol (Berl) 1984; 63: 287-295.
54. Galle P, Berry JP, Duckett S. Electron microprobe ultrastructural localization of aluminum in rat brain. Acta Neuropathol (Berl) 1980; 49: 245-247.

55. Bowen DM, Davidson AN. Changes in brain lysosomal activity, neurotransmitter related enzymes and other proteins in senile dementia. In: Katzman R, Terry R, Bick K, eds. Alzheimer's Disease: Senile Dementia and Related Disorders. New York: Raven Press, 1978: 421-425.

56. Kruck TPA, McLachlan DRC. Aluminum as a pathogenic factor in senile dementia of Alzheimer type: Ion specific chelation. Alzheimer Dis Assoc Disord 1988; 2: 209.

57. Kruck TPA, McLachlan, DRC. Aluminum as a pathogenic factor in senile dementia of the Alzheimer type: Ion specific chelation. In: Iqbal K, Wisniewski HM, Winblad B, eds. Alzheimer's Disease and Related Disorders. New York: Alan R. Liss (in press).

58. Finnegan MM, Lutz TG, Nelson $O$, et al. Neutral water soluble post-transition metal chelate complexes of medical interest: Aluminum and gallium tris (3-hydroxy-4-pyronates). Inorg Chem 1987; 26: 2171-2176.

59. De Boni U, Scott J, Crapper DR. Intracellular Aluminum Binding: A histochemical study. Histochemie 1974; 40: 31-37.

60. Wen GY, Wisniewski HM. Histochemical localization of aluminum in the rabbit CNS. Acta Neuropathol (Berl) 1985; 68: 175-184.

61. Kosik KS, Duffy LK, Dowling MM, et al. Microtubule-associated protein 2: Monoclonal antibodies demonstrate the selective incorporation of certain epitopes into Alzheimer neurofibrillary tangles. Proc Natl Acad Sci USA 1984; 81: 7941 -7945.

62. Siegle N, Haug A. Aluminum interactions with calmodulin. Evidence for altered structure and function from optical and enzymatic studies. Biochem Biophys Acta 1983; 744: 36-45.

63. Lukiw WJ, Kruck TPA, McLachlan Crapper DR. Aluminum and the nucleus of nerve cells. Lancet $i$ 1989: 781 .

64. Johnson GVW, Jope RS. Phosphorylation of rat brain cytoskeletal proteins is increased after orally administered aluminum. Brain Res 1988; 456: 95-103.

65. Johnson GVW, Jope RS. Aluminum alters cyclic AMP and cyclic GMP levels but not presynaptic cholinergic markers in rat brain in vivo. Brain Res 1987; 403: 1-6. 